\title{
Exploring the Lack of Funding for Coral Reef Research and its Effects on Coral Reef Management and Conservation
}

\author{
Jenna Bushnell ${ }^{1}$ and Soo Park" \\ ${ }^{1}$ Advanced Technologies Academy, Las Vegas, NV, USA \\ \#Advisor
}

$\underline{\text { ABSTRACT }}$

Climate change is greatly harming coral reefs (Gibbs and West, 2019). It is important to research how to help these coral reefs build resilience against climate change but research programs are severely underfunded (Johnston et al. 2020). This paper explored how lack of funding prevents scientists from saving coral reefs and how scientists themselves can be affected. The goal of this paper was to bring to light the struggles faced in the midst of underfunding to feasibly gain support from politicians and government officials to promote funding for these programs. Through three virtual interviews with two scientists and one college professor, I gathered personal experiences from these participants on how coral reefs are being affected today, why research is necessary, and how lack of funding prevents the restoration of these reefs. With the use of a thematic analysis, I was able to recognize common themes between the interviews in order to conclude how lack of program funding prevents scientists from managing and restoring these coral reef ecosystems. The initial assumption for this paper was that coral reef research is underfunded because coral reefs are considered less important, however, the analysis of the data for this paper concluded that all research programs are underfunded. In essence, marine biology, in general, is underfunded as opposed to mainly research on coral reefs. As a result, scientists can be very limited in their abilities to conduct research.

\section{Introduction}

Climate change is a big issue affecting the world today and it is not going away anytime soon (Wepener, 2020). Climate change is essentially a change in climate patterns that causes increased levels of carbon dioxide in the atmosphere; produced by the use of fossil fuels. These changes in the atmosphere can prove fatal to ecosystems across the world (Anthony, 2020). In particular, climate change is greatly impacting coral reef species (Gibbs and West, 2019). It is apparent to study how coral reefs are affected by climate change to better understand how coral reefs can build resilience against climate change and ultimately be protected.

All ecosystems are dependent upon the coral reef species and some places like Jamaica, are mourning the death of $95 \%$ of their coral reefs (Neufville, 1998). Without these coral reefs, ecosystems across the globe will suffer from the changes that will take place in aquatic ecosystems (Wepener, 2020). Other places such as China are also experiencing a $40 \%$ decrease in coral reef generic diversity (Cybulski et al. 2020). Coral reef diversity is the term that describes all of the organisms that rely on these coral reefs to live. According to the National Oceanic and Atmospheric Administration, "Fishes and other organisms shelter, find food, reproduce, and rear their young in corals" and "...restoring corals can change the trajectory of an entire ecosystem" (2019). Additionally, coral reefs have been "subject to mass coral bleaching" due to rising sea temperatures (Brown et al. 2020). Coral bleaching is a term that describes the process of coral reefs turning white from sea temperatures which are too hot for the algae on the reefs to produce food; which the corals need to survive. These are some of the few issues that coral reefs are facing making it apparent for these coral reefs to be protected. 
Although coral reef research is often undertaken to study climate change's effects on the coral reef species, it is generally terminated due to lack of funding (Jokiel and Cox, 1995). Understanding how to sustainably manage and conserve the coral reef species against climate change is greatly hindered by a lack of research being done. As a result, coral reefs are poorly understood (Johnston et al. 2020). Therefore, it is apparent to shed light on the underfunding of coral reef research programs so that research can be done to help these coral reefs build resilience against climate change and ultimately be protected from extinction. This study will ask the question: how has the underfunding of coral reef research impeded scientists' abilities to guide actions on coral reef management and conservation?

\section{Literature Review}

To understand this study on how much knowledge is lacking on coral reef management and conservation, it is necessary to look at the existing research on the subject. Many studies suggest that coral reefs are misunderstood because the research programs that study these corals are generally underfunded and; therefore, research is limited. Specifically, a study focusing on an Australian research institute which is an international influence on coral reef ecosystems and their declining health is expected to lose most of its government funding after 2021 (Morton, 2018). The Australian Research Council (ARC), an independent government agency, has funded the institute since its establishment in 2005, but in a public hearing on government expenditure in October of 2018, the institute was no longer to receive "a share of the latest round of funding" (Morton, 2018). As a result, the center will "lose its title as an ARC centre of excellence" making the institute's future plans for coral reef research improbable (Morton, 2018). This institute which is at the forefront of coral reef research will no longer be able to provide its groundbreaking findings for future use on coral reef conservation because it is losing its funding. Similarly, a study on how experts demand more effort to save coral reefs states, "good research and management programs for coral reefs are available...they just need the proper funding and political will to enact them" (Jones, 2016). The study explains, "The Coral Reef Conservation Act of 2000, which aimed to protect coral reefs and create programs to manage their conservation, has been plagued by political resistance and a severe lack of funding" (Jones, 2016). This suggests that coral reef research is often seen as less significant when it comes to finding funding. Both studies aim to bring to light the underfunding of research programs and how it is paramount that coral reefs be protected. They are limited, however, since they do not provide any insight on possible alternative ways to fund these programs and what studies are being done to help coral reefs build resilience to climate change. Rather, Morton and Jones discuss the need to provide funding to these research programs so that further research can be done.

Contrary to the studies conducted by Morton and Jones, research examining the factors that contribute to the management and conservation of coral reefs; specifically, their ability to build resilience against climate change does exist. A study on operationalizing the resilience of coral reefs states, "Ecosystem management frequently aims to manage resilience yet measuring resilience has proven difficult" (Mumby et al. 2014). The study explains that coral reef resilience is measured using ecological models that calculate factors such as "a coral reef's initial state, physical environment, and disturbance regime" (Mumby et al. 2014). In other words, how likely the coral reef is to successfully recover with these environmental factors taken into account. The study concludes that measuring coral reef resilience is difficult because "the efficacy of management interventions will likely change depending on the frequency and intensity of future climate-induced disturbance" (Mumby et al. 2014). Ultimately, resilience practices may work now, but with climate patterns frequently changing, these practices may not work forever. Similarly, a study on prioritizing resilience indicators to support coral reef management found that "managing coral reefs for resilience to climate change is a popular concept but has been difficult to implement because the empirical scientific evidence has either not been evaluated or is sometimes unsupportive of theory" and this leads to "uncertainty when considering methods and identifying priority reefs" (McClanahan et al. 2012). This suggests that there are theories as to how these coral reefs can build resilience to climate change, but there is no information that has been observed through experiments to confirm these theories. In other words, it is unclear how coral reefs can build resilience, which coral reefs should 
be helped first, and whether or not they will be effective for a durable amount of time. Therefore, these studies are limited as they do not discuss any factual ways for coral reefs to build resilience against climate change. Rather, they discuss how resilience is measured, theories to help these corals, and how efforts to help corals build resilience are challenging, and oftentimes information to do so is lacking. Thus, these research programs will need funding for years to come as the climate is constantly changing, and the knowledge on how to manage and conserve these coral reefs is often speculation. Research that cannot be proven without the proper funding.

Therefore, some studies argue that lack of exploration due to underfunding is the cause of coral reefs being poorly understood, and others argue that lack of experimentation is the cause for them being misunderstood, both studies are limited due to lack of research. Few studies analyze what specific and factual ways can be implemented to help coral reefs build resilience against climate change, and lack of funding is often the cause of limitations in research abilities. Future research should also aim to explore what can be done to help find specific ways for coral reefs to gain resilience against climate change so they can be sustainably managed and conserved. This study will attempt to fill the gap in research by asking the question: how has the underfunding of coral reef research programs impeded scientist's abilities to guide actions on coral reef management and conservation?

Thus, in this study, data will be collected on the current issues with funding coral reef research through an exploratory case study in which I will conduct forty-five minute to hour-long, virtual interviews on three college professors and scientists regarding the reasons why coral reef research is necessary and how much research is underfunded. The information will then be transcribed from the recorded interviews. This will allow me to analyze how many programs experience underfunding and how much research is accomplished in these areas. With this information, I will be able to conclude the causes for the underfunding of coral reef research programs and how lack of research impedes scientists' abilities to guide actions on coral reef management and conservation. My study will gather information on this area and ultimately fill the gap in knowledge by shedding light on the struggles that scientists face in coral reef research because of underfunding and possibly allow politicians and government officials to promote funding in these areas. I have hypothesized that coral reef research is underfunded because it is seen as less significant and funding often goes elsewhere. The inquiry will not mention the names of any participants to protect user anonymity.

\section{Methods}

\section{Overview}

The research is an exploratory case study method that contains three forty-five minute to hour-long, virtual, interviews along with a thematic analysis used to analyze the data found in the interviews. Exploratory case studies serve to investigate and better understand an existing problem that is not clearly defined (Baxter et al. 2010). This study is an exploratory case study of three college professors or scientists who specialize in marine biology, general biology, and coral ecology. This chosen method was used to effectively explore the importance of coral reef research and the struggles that research facilities face from lack of funding. Ultimately, this study allows for a better understanding of how lack of funding prevents future research and actions that will help coral reefs build resilience against climate change. Looking at this knowledge through the exploratory case study was the most effective way to interpret the data found in the interviews. The data found in the interviews were then analyzed with thematic analysis to interpret any patterns that may be present in the research.

\section{Interviews}

To gather data on coral reef research programs and the issues that follow from lack of program funding, I conducted interviews as the first part of the exploratory case study. Interviews serve to collect one person's perspective and 
experiences on an issue or situation so that it can be better understood (Frances et al. 2009). Interviews must consist of discipline-specific interviewees and must ask non-threatening, factual questions which relate to the purpose of the research (Frances et al. 2009). Additionally, the questions must not be written so that they can be answered with a simple yes or no, they must be open-ended questions so that further elaboration and information can be touched upon by the interviewee and examined by the interviewer (Frances et al. 2009). Interviews were selected as the primary form of data collection because they allow for a one-on-one conversation with individuals who can provide a personal experience with the issue at hand. By conducting interviews, I was able to get insight from participants who have experienced or are aware of the effects that are imposed by underfunded research programs. Ultimately, this gave me an understanding of the importance of coral reef research funding and why this research is necessary. Hence, interviews were used as they are intended to gain first-hand knowledge from an interviewee on a certain issue or topic.

To conduct these interviews, I had to first find participants who were able to answer questions on the topic of my research. Since my research is on coral reef ecosystems, I needed to find participants who work with coral reefs and those who know sufficient information about them. Therefore, as stated earlier, I asked three college professors or scientists who specialize in marine biology, general biology, and coral ecology. The participants also had to be knowledgeable of the underfunding of coral reef research. Thus, the participants I asked for interviews fell into these categories and knew sufficient information about coral reef ecosystems and the underfunding of coral reef research programs. Once these participants were chosen, the interviews were established. In total, one college professor and two scientists were chosen.

The interviews asked questions categorized into four groups: the underfunding of coral reef research programs, why coral reef research is important, how coral reefs are being affected today, the struggles scientists face with lack of funding, and how much knowledge is lacking on coral reef resilience against climate change. All interviews asked the same twenty questions which fell into the four groups above to get the participant's experiences in these areas. The questions followed the format discussed previously as they were open-ended, non-threatening questions that relate to the purpose of this research paper (Frances et al. 2009). Lastly, each interview was forty-five minutes to an hour-long and conducted virtually over video calls. This information allowed me to conclude why coral reef research is necessary and spread awareness for the underfunding of this research and hopefully gain support from politicians and government officials in funding these research programs.

\section{Thematic Analysis}

Once the interviews were conducted, the second part of the exploratory case study was the use of qualitative thematic analysis to interpret the data found in the interviews. Thematic analysis is a method that allows for identifying, analyzing, and reporting patterns within data (Braun and Clarke, 2006). Therefore, a thematic analysis was used to interpret any patterns in the participant's experiences with coral reef research found in the interviews.

While applying a thematic analysis to the data found in the interviews, I focused on; first, the patterns within the experiences that the participants have had with coral reef research and underfunding. These patterns included similarities in experiences involving how many research programs are underfunded and what challenges are faced with lack of program funding. These challenges would relate to the reasons why coral reef research is necessary. Once the first step was completed, I analyzed these similarities in experiences to conclude why coral research is necessary and what they are mostly affected by today. Similar experiences were categorized into groups and each group was given a subject that allowed me to interpret what factors contribute to the underfunding of coral reef research and why this research is important. Since a thematic analysis distinguishes patterns in data, this method was the most effective at analyzing the data in the interviews. 


\section{Findings}

Before discussing the findings from coding the data, we must first discuss the common themes that emerged. A total of eight themes emerged from the three interviews. The themes and their definitions are in the table below.

Table 1: Definition of Themes

\begin{tabular}{|l|l|}
\hline Theme & Definition \\
\hline Observation & $\begin{array}{l}\text { Experiences from seeing the destruction of coral reef eco- } \\
\text { systems first-hand through coral restoration projects or re- } \\
\text { search projects. }\end{array}$ \\
\hline Recycling & Recycling of nutrients done by coral reefs. \\
\hline Pollution & Garbage in the ocean. \\
\hline Ocean Temperature & $\begin{array}{l}\text { The warming temperatures of the ocean; caused by climate } \\
\text { change. }\end{array}$ \\
\hline Coral Reef Importance & The reasons why we need coral reefs. \\
\hline Symbiotic Relationships & $\begin{array}{l}\text { Organisms that benefit from the coral reefs but do not harm } \\
\text { the coral reefs. }\end{array}$ \\
\hline Political Will & $\begin{array}{l}\text { Lack of funding from the government for coral research } \\
\text { and restoration projects because of a lack of persistence to } \\
\text { fund it. }\end{array}$ \\
\hline Limitations & $\begin{array}{l}\text { Issues faced by research facilities and coral reef research } \\
\text { projects from lack of funding. }\end{array}$ \\
\hline
\end{tabular}

The results of the interviews were organized in the table below.

Table 2: Summary of the Three Interviews

\begin{tabular}{|l|l|l|}
\hline Interview Participants & Experiences from Participants & Corresponding Theme \\
\hline Scientist 1 & $\begin{array}{l}\text { Saw coral reefs suffer mortality in Costa Rica dur- } \\
\text { ing a coral restoration project. }\end{array}$ & Observation \\
\hline $\begin{array}{l}\text { Describes coral reef's ability to recycle nutrients, } \\
\text { including carbon molecules. Coral reefs remove } \\
\text { nutrients and carbon from the ocean but most of it } \\
\text { is recycled through the food web and eventually }\end{array}$ & Recycling \\
\hline
\end{tabular}




\begin{tabular}{|c|c|c|}
\hline & $\begin{array}{l}\text { back to the ocean. This recycling provides insights } \\
\text { into their resilience } \\
\text { Believes we should get rid of plastics because they } \\
\text { are polluting the ocean. } \\
\text { Supports research showing that hot ocean temper- } \\
\text { atures put stress on coral and cause them to bleach. } \\
\text { Explains that coral reefs support many different } \\
\text { organisms and promote biodiversity in the ocean. } \\
\text { They provide food for humans. } \\
\text { Encountered situations where people need help } \\
\text { from politicians to raise money for research. } \\
\text { Experienced inability to bring colleagues on a reef } \\
\text { restoration project because of lack of funding. }\end{array}$ & $\begin{array}{l}\text { Ocean Temperature } \\
\text { Coral Reef Importance } \\
\text { Political Will } \\
\text { Limitations }\end{array}$ \\
\hline Scientist 2 & $\begin{array}{l}\text { Witnessed the degradation and mass mortality of } \\
\text { coral reefs in Australia's northern section of the } \\
\text { Great Barrier Reef; not previously seen before. } \\
\text { Describes how plastic is not as much of an issue } \\
\text { for corals in particular compared to ocean temper- } \\
\text { atures. Corals don't eat plastic but the organisms } \\
\text { that live on corals do. } \\
\text { Remarks that climate change is at the core of why } \\
\text { we're seeing these increases in ocean temperatures } \\
\text { globally which leads to mass bleaching events and } \\
\text { the eventual death of coral reefs. } \\
\text { Mentions that coral reefs are like nurseries of the } \\
\text { sea. They provide habitats because of their com- } \\
\text { plexity and are necessary for the food chain. } \\
\text { Explains how corals rely on symbiotic relation- } \\
\text { ships between algae that live within their skins. As } \\
\text { temperatures warm up, that relationship breaks } \\
\text { down and those algae start producing bad things } \\
\text { instead of food or energy for the coral. The coral } \\
\text { gets rid of the algae and then starves to death. } \\
\end{array}$ & Symbiotic Relationships \\
\hline
\end{tabular}




\begin{tabular}{|c|c|c|}
\hline & $\begin{array}{l}\text { Clarifies that research materials and other technol- } \\
\text { ogies are extremely expensive. Without the proper } \\
\text { funding, experimentation and exploration are even } \\
\text { more limited especially during the COVID-19 } \\
\text { pandemic. }\end{array}$ & \\
\hline \multirow[t]{6}{*}{ College Professor } & $\begin{array}{l}\text { Participated in a movement to restore the Florida } \\
\text { Keys reefs from pollution, human impact, and } \\
\text { bleaching events. }\end{array}$ & Observation \\
\hline & $\begin{array}{l}\text { Explains how we need to grow corals and put them } \\
\text { back on the reefs until we fix the environment. Pol- } \\
\text { lution and many other factors are harming the ar- } \\
\text { eas that these reefs live in. }\end{array}$ & Pollution \\
\hline & $\begin{array}{l}\text { Observed research showing the need to decrease } \\
\text { ocean temperatures because the hot temperatures } \\
\text { are harming reefs. }\end{array}$ & Ocean Temperature \\
\hline & $\begin{array}{l}\text { Views the protection of reefs as necessary because } \\
\text { humanity will die without them. They form life for } \\
\text { many different animals and help the ocean stay } \\
\text { healthy. }\end{array}$ & Coral Reef Importance \\
\hline & $\begin{array}{l}\text { Clarifies that we know enough information about } \\
\text { climate change's effects on coral reefs to take ac- } \\
\text { tion; we just lack the political will. }\end{array}$ & Political Will \\
\hline & $\begin{array}{l}\text { Experienced the inability to buy a decompression } \\
\text { chamber during their Florida Keys project. Re- } \\
\text { search facilities can't buy the proper equipment } \\
\text { without funding. }\end{array}$ & Limitations \\
\hline
\end{tabular}

As stated earlier, three participants consisting of two scientists and one college professor were interviewed on their experiences with coral reef research, underfunding, and whether they think future research is necessary. Their names have not been included in this study. The first column states which participant is being examined; thus, each row in the table represents a single participant and their experiences in the areas mentioned above. The second column contains 6-7 short explanations of the key experiences from the interviews. They were included in the table as the participant's cited their experiences working with coral reefs, the dangers coral reefs are facing, the reasons we need coral reefs, and the struggles they and other scientists face with underfunding. The third column lists the theme which corresponds to the experiences in column two. These themes, listed and explained in table one, were assigned based on the major occurrences the participant had discussed during the interview. They are significant as they represent common struggles and experiences between people who work in the field of science and specifically those who work with coral reef ecosystems. 
This table condenses the experiences of each participants' interview into a few important events about their experiences working with coral reefs. Through the table, it is possible to recognize similar experiences of the participants from the recurring themes within the data set. These themes, when thematically analyzed, can help identify how underfunding affects scientists' abilities to take guide actions on coral reef management and conservation.

\section{Results}

This section will discuss the results of the thematic analysis. While analyzing the data, there were a total of six themes repeated consistently out of the eight themes. These recurring themes represent whether coral reef ecosystems are in danger, what is harming them, whether coral reef research is necessary, and how lack of funding affects coral reef research.

\section{Recurring Theme 1: Observation}

Observation was a recurring theme experienced by all three participants who had participated in research projects regarding the restoration or exploration of coral reefs. In all three experiences, the participants cited seeing first-hand the destruction that coral reef ecosystems are facing from climate change (mass bleaching events). As defined in table one, observation refers to seeing the destruction of coral reef ecosystems first-hand; in this case, through coral restoration projects and other research projects. These experiences usually involved coral reef ecosystems dying from mass bleaching events caused by water temperatures that are too hot for the coral reefs to live in.

\section{Scientist 1 states,}

"I worked on a coral restoration project in Costa Rica. So, I see the corals often and I get to observe them directly in terms of how they're doing. For Costa Rica, we have already seen multiple times when the corals have suffered mortality from high temperatures; and they bleach."

\section{Scientist 2 states,}

"I was one of the few people who were diving through one of the most ecological tragedies of our time and witnessed the coral bleaching first-hand every day for months. It hammers how fragile the world is and how fragile nature is and the importance that we have relationships with it and do the right thing."

\section{College Professor states,}

"While working on a project in the Florida Keys, this was the very beginning

of finding coral disease, human impacts, pollution, and climate change. Ultimately, all these factors are harming reefs."

All three participants recall witnessing the issues that are facing coral reef ecosystems. Scientist one sees often how corals are doing and explains that they have suffered multiple times from hot water temperatures which cause them to bleach. Scientist one has seen multiple times the mortality of coral reefs. Scientist two witnessed coral bleaching for months at a time while diving for research purposes. The college professor witnessed several impacts that are harming coral reefs during a research project. With this, we can conclude that coral reef ecosystems are at harm from the experiences stated by all three participants which they observed first-hand.

\section{Recurring Theme 2: Pollution}

Pollution was a recurring theme discussed by all three participants. In this case, pollution is representative of the amount of garbage in the ocean. These discussions usually involved how pollution in the ocean; garbage, is affecting coral reefs. 


\section{Scientist two states,}

"Plastic is bad for things that eat it, corals don't eat plastic. There's so much plastic in the ocean. I've been to some of the most remote places in the world, places that take 30 days to get to by boat that when you get there no humans walked on it in years, if ever, and there's plastic everywhere. It's a massive issue but it's not necessarily something that's directly influencing corals in particular. It certainly is impacting things that live on coral reefs. And I'm sure you get nets that get caught in the coral and can break down coral and smother them. But temperature is a million times worse for the coral reefs."

Scientist two explains that pollution is certainly a huge issue for the ocean and the organisms that live in it; but, it may not be as harmful to the coral themselves compared to ocean temperatures. They also explain that pollution may be more harmful to the organisms that live on the reefs than the reefs in particular. All three participants reported similar opinions that we need to stop polluting our oceans but it is unclear whether pollution is as much of an issue for coral reefs as ocean temperatures. With this, we can conclude that garbage pollution in the oceans is a huge issue but it may not always directly harm coral reefs except in certain situations where pieces of garbage come into contact with the reef and break it down. It does; however, indirectly affect them as it harms the organisms that live on the reef which helps keep the many ecosystems within the reef flourishing.

\section{Recurring Theme 3: Ocean Temperature}

To continue our discussion on what is harming reef ecosystems, ocean temperature was a recurring theme between all three participants. Ocean temperatures, as explained in table one, is the warming of the ocean caused by climate change. The warming of ocean temperatures was discussed by all three participants and typically involved ocean temperatures becoming too hot for coral reefs to survive which leads to the bleaching of the reefs.

\section{Scientist 1 states,}

"The water in the ocean gets too hot which causes a lot of stress on the coral. And they

bleach and if they stay bleached for too long, they die. It's what happened on the corals in many, many locations and it's been getting worse over time."

Scientist one explains that when ocean temperatures get too hot, the coral bleaches and cannot recover if the temperatures stay too hot. All three participants discussed similar explanations as to how ocean temperatures are affecting coral reefs at large scales and causing them to bleach and die. With this information, it is clear that hot ocean temperatures, which cause coral bleaching, are one of many very harmful impacts on coral reef ecosystems.

\section{Recurring Theme 4: Coral Reef Importance}

We will now look at why we need to protect coral reef ecosystems. Coral reef importance was a recurring theme between all three participants. As explained in table one, coral reef importance includes the reasons why we need coral reefs. Among all three participants, the discussion usually involved coral reefs being important because they help sustain life on earth.

\section{Scientist 1 states,}

"They're the rainforest of the sea. They're super biodiverse. They support so many different organisms during some part of their life cycle. So they are big attractors in the ocean, the little fish, the big fish, everything that comes to these big ecosystems that are built by corals. If the corals die, those reefs start eroding away. So, the first thing that happens, you lose your biodiversity, then you lose your fishing grounds, then people go hungry." 


\section{Scientist 2 states,}

"Coral reefs are sort of the nurseries of the sea. Corroboration in our oceans make up about $1 \%$ of the ocean floor, a really small amount. But they're so incredibly diverse. They provide so much habitat because of their complexity that $1 / 3$ of all life in our ocean uses the coral reef, at one point in their lifespan. They're incredibly important for a mass majority of fish in our oceans."

\section{College Professor states,}

"We need to protect coral reefs because humanity will die without them. They form life for many different animals and they help the ocean stay healthy. We used to be interested in reefs to find out how they work. Now we need to know how to keep coral reefs from going extinct."

Scientist one explains that the biodiversity of coral reefs supports many organisms within the ocean and are essential as they support several different species at some point in their life and without the reefs, fish will leave and people will go hungry. Scientist two discusses a similar explanation as to how diverse coral reefs are and how they provide habitat for other organisms to live off at some point in their life. The college professor also describes a similar explanation as to how humanity will not survive without the reefs because they provide a place for other organisms and are essential for keeping the ocean healthy. With this, we can conclude that coral reef ecosystems need to be protected because they help sustain life in the ocean and help provide food for humans.

\section{Recurring Theme 5: Political Will}

Political will was a recurring theme between two of the three participants. In this case, political will, as stated in table one, is a lack of government funding for coral reef research and restoration projects because there is no persistence in providing funding. Two of the three participants mentioned political will in their interviews. Specifically, scientist one and the college professor mentioned similar explanations about lack of funding being an issue because of a need for political help and more drive from the government to provide the funding.

\section{Scientist 1 states,}

"Most of the reefs are in really poor countries. It's hard to get funding for places like that. That's where a lot of groups come together and say, we have a big goal, we need this amount of money, we need all these people from these different groups to be involved. And we need politicians to help us. We need political help, to raise the money... We haven't done that for coral reefs yet."

\section{College Professor states,}

"Research programs are all underfunded. Marine biology, in general, is underfunded. We know enough to know that we need to take action; we just lack the political will. Congress says we need more research to be able to start implementing but then won't fund that research or the programs that do that research."

Both scientist one and the college professor explain that we need the proper funding to be able to do the research and learn more about how to protect coral reefs. They both explain that there is a need for help from politicians and congress to fund these programs and the research involved so that we can start implementing protection. With this, we can conclude that science, in general, can be underfunded and, in some cases, the reasoning can be because the government lacks the will to fund these programs.

\section{Recurring Theme 6: Limitations}

Limitations were a recurring theme between all three participants. As stated in table one, limitations include the setbacks that scientists, research projects, and research programs face from lack of funding. Two of the three participants 
reported experiencing certain setbacks in their research from underfunding and one explained certain setbacks other scientists may face from lack of funding. These discussions usually involved the inability to buy or use certain equipment for research purposes or having a limited team of scientists doing the research.

\section{Scientist 1 states,}

"It makes me sad that I can't take everyone out with me. We don't have the money."

\section{Scientist 2 states,}

"One of the things that comes to mind is that doing genetic research can be incredibly expensive. Doing genome reading, and coding can cost hundreds of thousands of dollars. Without funding to be able to do that, we can be quite limited in the questions that we can ask and properly answer"

\section{College Professor states,}

"While working on the Florida Keys project, we were unable to buy a decompression chamber. You can't buy the proper equipment without the funding."

Both scientist one and the college professor recall experiencing the inability to do certain things with their research because of lack of funding. Scientist one explains that they are unable to take colleagues on restoration projects because they don't have the money. The college professor explains that they were unable to buy a decompression chamber during their research in the Florida Keys because there also were not enough funds. Scientist two explains certain situations where lack of funding can limit research abilities to find answers for that research. With this, we can conclude that lack of funding prevents certain questions from being answered and limits the research that scientists can do; in this case, on coral reefs. It can also limit the number of resources available for scientists doing the research.

\section{Limitations}

The biggest limitation of the research was the sample size. Due to limitations with the COVID-19 pandemic, many research facilities have had to stop research projects because of the pandemic which made it difficult to contact research facilities for any participants. It has also been difficult to find participants on their own who are knowledgeable of the topic of my research and willing to help during such difficult times. Having more participants to interview would have made the sample size larger and could have possibly produced more accurate findings. Another limitation would be human error. As the researcher, human error could have occurred during the analysis section of my paper. I could have missed certain themes or important information said by the participants while analyzing the interviews and coding the data. This would have made the data set less accurate.

\section{Conclusion}

The results show several conclusions on coral reef research. First, the results from all sources of my paper, those in the literature review and from the interviews, showed that coral reef research is necessary. As stated by all sources, coral reefs play an important part in the survival of all living things, and all organisms in the ocean use the coral reef at some point in their life. Secondly, the results show that climate change is one of the biggest factors affecting coral reefs today. As stated in all sources, warming ocean temperatures, caused by climate change, are causing coral reefs to bleach, starve, and eventually die leading to mass bleaching events and high mortality rates. Thirdly, the results showed that coral reef research is underfunded; but, my original assumption was not entirely true. Originally, I assumed that coral reef research was solely underfunded; but, as stated in two of my interviews, marine science, in general, is underfunded as opposed to mainly research on coral reefs. So, coral reef research is underfunded causing 
setbacks in research abilities and the conservation of coral reefs, but that is because marine science, in general, is underfunded and not always because coral reefs are seen as the last priority. Lastly, the main reason found for the underfunding of coral reef research was the lack of political will. In parts of my literature review and two of the three interviews mentioned the need for support from politicians and government officials to fund these research programs. Therefore, a possible solution to the issues discussed in this paper would be simply promoting more funding to marine science research projects by bringing politicians and groups of people together and advocating for the protection of our planet and specifically our oceans. It is also important to educate the public on the issues facing our oceans so that people who may not directly rely on coral reefs can still understand why it is so important to do what they can to help out the planet even a little bit.

In future research of my paper, I would include participants from several different research facilities who study coral reefs including those around the world where coral reefs are most abundant. Since these research facilities are the ones who are granted the funding, they would provide more variety of information on the underfunding of coral reef research. Also, since all of my participants resided in the United States, these are only experiences of participants living in the United States rather than in places where there are far more coral reef ecosystems. There was one case where one of my participants had done coral reef research in another country. Scientist one stated in the interview, "...it's hard to get funding in these third-world countries. Third-world countries are where most of our reefs are. In the US all of our reefs are in Florida, Hawaii, and then a few island states like Samoa. But most of the reefs are in really poor countries...it's hard to get funding for places like that and it's hard to have research facilities in places like that." Therefore, in future research of my paper, I would include participants from all over the world where coral reefs live to gain insight on their experiences with lack of funding and what their coral reefs are going through. This would provide far more accurate results as coral reefs live in many places other than the United States.

The goal of this paper was to shed light on the underfunding of coral reef research programs and the struggles that these scientists face with the lack of funding, in hopes of gaining support from politicians and government officials to promote funding for these programs.

\section{Acknowledgments}

I would like to thank Dr. Park for providing me with feedback and support during the research process. I would also like to express my gratitude to the college professor and scientists who participated in this study and to all of the people who are, or have, experienced similar setbacks to the ones addressed in this paper.

\section{References}

ANTHONY L. The sixth extinction. Canadian Geographic. 2020;140(5):58-67. Accessed January 26, 2021. http://search.ebscohost.com/login.aspx?direct=true\&db=asn\&AN=144817550\&site=ehost-live.

Baxter, Pamela \& Jack, Susan. (2010). Qualitative Case Study Methodology: Study Design and Implementation for Novice Researchers. Qualitative Report. 13. 10.46743/2160-3715/2008.1573.

Braun, Virginia \& Clarke, Victoria. (2006). Using thematic analysis in psychology. Qualitative Research in Psychology. 3. 77-101. 10.1191/1478088706qp063oa.

Brown CJ, Taylor W, Wabnitz CCC, Connolly RM. Dependency of Queensland and the Great Barrier Reef's tropical

fisheries on reef-associated fish. Scientific Reports. 2020;10(1):1-11. doi:10.1038/s41598-020-74652-2

“Coral Reef Ecosystems.” Coral Reef Ecosystems | National Oceanic and Atmospheric Administration, National

Oceanic and Atmospheric Administration, Feb. 2019, www.noaa.gov/education/resource-

collections/marine-life/coral-reef-ecosystems.

Crosby, M.P., G.R. Gibson, and K.W. Potts (eds). 1996.A Coral Reef Symposium on Practical, Reliable, Low Cost 
Monitoring Methods for Assessing the Biota and Habitat Conditions of Coral Reefs, January 26-27, 1995.Office of Ocean and Coastal Resource Management, National Oceanic and Atmospheric Administration, Silver Spring, MD.

Cybulski, Jonathan D., et al. "Coral Reef Diversity Losses in China's Greater Bay Area Were Driven by Regional Stressors." Science Advances, American Association for the Advancement of Science, 1 Oct. 2020, advances.sciencemag.org/content/6/40/eabb1046.

Frances, Ryan \& Coughlan, Michael \& Cronin, Patricia. (2009). Interviewing in qualitative research. International Journal of Therapy and Rehabilitation. 16. 309-314. 10.12968/ijtr.2009.16.6.42433.

Gibbs DA, West JM. Resilience assessment of Puerto Rico's coral reefs to inform reef management. PLoS ONE. 2019;14(11):1-21. doi:10.1371/journal.pone.0224360

Johnston NK, Campbell JE, Paul VJ, Hay ME. Effects of future climate on coral-coral competition. PLoS ONE. 2020;15(8):1-16. doi:10.1371/journal.pone.0235465

Jones, Caleb. Experts Demand More Effort to Save Coral Reefs, Phys.org, 25 June 2016, phys.org/news/2016-06-experts-demand-effort-coral-reefs.html.

McClanahan TR, Donner SD, Maynard JA, et al. Prioritizing Key Resilience Indicators to Support Coral Reef Management in a Changing Climate. PLoS ONE. 2012;7(8):1-7. doi:10.1371/journal.pone.0042884

Morais, Juliano \& Medeiros, Aline \& Santos, Bráulio. (2018). Research gaps of coral ecology in a changing world. Marine Environmental Research. 140.10.1016/j.marenvres.2018.06.021.

Morton, Adam. "Coral Scientists Decry Loss of Funding for Leading Australian Reef Institute." Nature News, Nature Publishing Group, 5 Nov. 2018, www.nature.com/articles/d41586-018-07270-8.

Mumby PJ, Wolff NH, Bozec Y-M, Chollett I, Halloran P. Operationalizing the Resilience of Coral Reefs in an Era of Climate Change. Conservation Letters. 2014;7(3):176-187. doi:10.1111/conl.12047

Neufville Z. Reef requiem. New Internationalist. 1998;(307):6. Accessed January 26, 2021. http://search.ebscohost.com/login.aspx?direct=true \&db=asn\&AN=1277077\&site=ehot-live.

Wepener V. Statement from world aquatic scientific societies on the need to take urgent action against humancaused climate change, based on scientific evidence. African Journal of Aquatic Science. 2020;45(4):383385.doi:10.2989/16085914.2020.1824388 